\title{
FEED-FORWARD EQUALIZATION OF SOUND RADIATION FROM A VIBRATING PLATE
}

\begin{abstract}
SUMMARY
In this paper an adaptive single input - multiple output feed-forward system for sound radiation from a vibrating plate is investigated. Finite impulse response filters are used to generate control signals for each actuator based on the common input signal. The filters are updated with the Filtered-x LMS algorithm in order to minimize the instantaneous squared value of the difference between the sound pressure measured at the specified point in the acoustic field, and the desired signal being the input signal filtered by the assumed secondary path transfer function model. Performance of the system is experimentally verified and obtained results are reported.
\end{abstract}

Keywords: vibrating plate, sound radiation, adaptation, feed-forward, equalization, active noise control, playback

\section{EQUALIZACJA DŹWIĘKU EMITOWANEGO Z POWIERZCHNI DRGAJĄCEJ PEYTY}

$W$ pracy przedstawiono adaptacyjny uktad o jednym wejściu $i$ wielu wyjściach ze sprzężeniem zwrotnym wyprzedzajacym w zastosowaniu do emisji dźwięku z powierzchni drgajacej ptyty. Filtry o skończonej odpowiedzi impulsowej zostaty zastosowane do generowania sygnałów sterujacych dla aktuatorów o wspólnym sygnale wejściowym. Wykorzystano algorytm LMS do minimalizacji wartości kwadratu różnic pomiędzy zmierzonym ciśnieniem $w$ wybranych punktach pola akustycznego a sygnatem zadanym będacym sygnałem wejściowym. Jakość systemu została zweryfikowana eksperymentalnie, wyniki weryfikacji zostaly przedstawione $w$ pracy.

Stowa kluczowe: drgajaca płyta, emisja dźwięku, adaptacja, sprzężenie zwrotne wyprzedzające, equalizacja, aktywne sterowanie dźwiękiem

\section{INTRODUCTION}

Sound source is one of the most crucial components of an Active Noise Control (ANC) system. Its properties should be adequate to the given specific environmental conditions. Otherwise, the overall project fails. For some applications the sound source is subject to dust, high temperature, high humidity or precipitation. If feasible, it should be then moved to a less harsh area, for the control of exhaust noise (Kuo and Morgan 1996). However, in most cases, such a solution does not apply. Sound sources tolerant to difficult environmental conditions can also be useful for other problems including the generation of voice messages and alarms in an industrial environment.

The idea of using vibrating plates as secondary sound sources in ANC is well known (Hansen and Snyder 1997, Fahy and Gardonio 2007, Elliott 2001, Pietrzko 2009). However, vibrating plates are harder to control than loudspeakers because of nonlinearity and high variations of amplitude response (El Kadiri et al. 1999, Saha et al. 2005). Radiation from vibrating plates are still in scientific interests (Cieślik and Bochniak 2010). For many applications multiple actuators are mounted on a single plate, what complicates the control problem further (Wiciak 2008). The system becomes multichannel, and the commonly used Filtered-x LMS algorithm for noise control requires several actual secondary path models to operate stably. By applying an additional controller the acousto-electric plant can be decoupled and each secondary path can be controlled separately. Such an approach can also be used to equalize the frequency response of the secondary path to make ANC more efficient.In this paper an adaptive single input - multiple output feed-forward system for sound radiation from a vibrating plate is investigated. Finite impulse response filters are used to generate control signals for each actuator based on the common input signal. The filters are updated with the Filtered-x LMS algorithm in order to minimize the instantaneous squared value of the difference between the sound pressure measured at the specified point in the acoustic field, and the desired signal being the input signal filtered by the assumed secondary path transfer function model. The model should reflect the desired dynamics of the vibrating plate. Such an approach is proposed to equalize the sound radiation from the vibrating plate. The performance of the system is experimentally verified and the obtained results are reported. It is announced that the results of this research are attractive for an ANC or a playback system.

\section{PLANT}

A rectangular aluminium vibrating plate of dimensions $400 \times 500 \times 1 \mathrm{~mm}$ is mounted on a wall of a laboratory room. All edges are firmly clamped to a double wooden frame with screws and a rubber isolator. Although the displacement and its derivative at the edges should be zero, because

\footnotetext{
* Institute of Automatic Control, Silesian University of Technology, Gliwice, Poland; Krzysztof.Jan.Mazur@polsl.pl; Marek.Pawelczyk@polsl.pl
} 
the fit is not perfect and the frame resonates as well, inputoutput identification methods instead of physical modelling will be used. The sound radiated from the plate is measured by a microphone located $1.2 \mathrm{~m}$ away from the plate at the centre line in the laboratory room.

Nine equally spaced MFC elements were installed symmetrically on the plate to excite the lowest vibration modes. From those elements, three patches were chosen experimentally as presented in Figure 1. They originally excite $(2,2)$ and $(2,1)$ modes, and corresponding higher modes. They have been found particularly useful to improve sound radiation in the $250-500 \mathrm{~Hz}$ frequency band, being of concern in this paper. The MFC patches work in the bending mode, i.e. they bend when appropriate voltage is applied (Smart Material 2010). MFC patches using the d33 effect are used. This type of element has a higher power-per-size ratio, but very high voltage $(-500 \mathrm{~V}$ to $1500 \mathrm{~V})$ is needed.

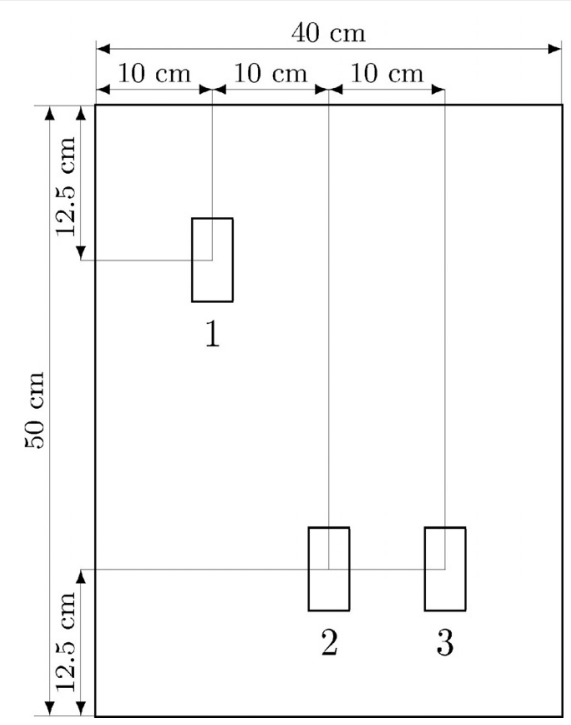

Fig. 1. Positions of MFC elements on the plate

Amplitude responses of the plant paths $S_{i}$ as defined between the signals exciting the vibrating plate separately by subsequent actuators, and the microphone measurement are presented in Figure 2. The paths include also properties of acoustic filed present in a reverberant enclosure. Hence, the plate resonances are not clearly observed. Higher resonances are additionally suppressed due to the presence of the low-pass antialiasing filter (for the considered set up there should be about 30 resonances below $1 \mathrm{kHz}$ ). The identification of these paths was performed with the same structure as that used for control. Each actuator was connected to a different electric path, including an amplifier. A multisine signal in full $0-1000 \mathrm{~Hz}$ frequency range was used to excite each channel. Only one path was identified at a time. High variations of path frequency responses are due to vibrating plate resonances, positions of actuators on the plate, and laboratory room reverberant properties. Because of the complexity of the responses, sound quality generated using the raw vibrating plate is poor. Without the appropriate compensation, ANC systems with the Filtered-x LMS algorithm would suffer from a very slow adaptation to guarantee stable operation. The problem is complicated further because of coupled control channels. Such behaviour would also make the vibrating plate unsuitable for sound playback.

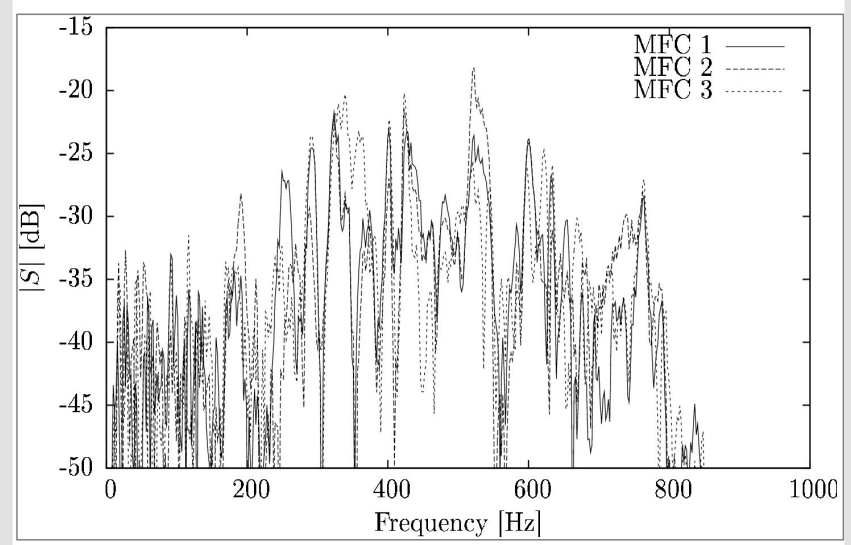

Fig. 2. Amplitude response of secondary paths characterised by MFC elements at different locations

\section{FEED-FORWARD EQUALIZATION}

\subsection{Control algorithm}

For equalizing sound radiation from the vibrating plate, a single input - multiple output adaptive feed-forward control system was chosen as presented in Figure 3. The notation is as follows: $i$ - discrete time instant, $x(i)$ - input signal, $d(i)$ - desired signal at the position of the microphone, $e(i)$ - error signal being the difference between the desired signal and the sound acquired by the microphone, $W_{1}-W_{3}$ - equalizing filters used to drive the selected MFC patches, $H$ - model of the desired response, $S_{j}$ - secondary paths due to different MFC actuators, $\hat{S}_{j}-$ models of respective secondary paths.

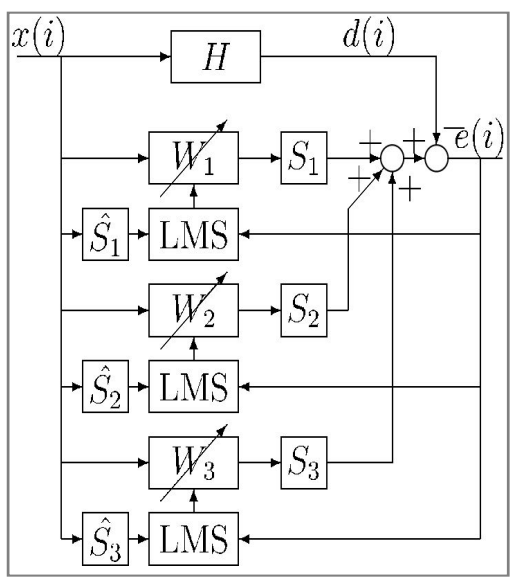

Fig. 3. Control system diagram 
Parameters of the $j$-th equalizing filter, stored in vector $\underline{w}_{j}(i)=\left[w_{j, 0}(i), w_{j, 1}(i), \ldots, w_{j, N-1}(i)\right]^{T}$ are updated with the Normalized Leaky LMS algorithm (Pawełczyk 2005):

$$
\underline{w}_{j}(i+1)=\alpha \underline{w}_{j}(i)-\mu \frac{\underline{r}_{j}(i)}{\underline{r}_{j}^{T}(i) \underline{r}_{j}(i)+\zeta} e(i)
$$

where $\mu$ is the convergence coefficient $0<\alpha<1$ is the leakage coefficient, and $\zeta$ is a parameter protecting against division by zero in case of a lack of excitation. In this equation $\underline{r}_{j}(i)=\left[r_{j}(i), r_{j}(i-1), \ldots, r_{j}(i-M+1)\right]^{T}$ is a vector of regressors of the filtered-reference signal obtained as:

$$
\underline{r}_{j}(i)=\hat{s}_{j}(i)^{T} \underline{x}_{r}(i)
$$

where $\hat{s}_{j}(i)=\left[\hat{s}_{j, 0}(i), \hat{s}_{j, 1}(i), \ldots, \hat{s}_{j, M-1}(i)\right]^{T}$ is a $j$-th secondary path filter impulse response model, $\underline{x}_{r}(i)=[x(i), x(i-1), \ldots, x(i-M+1)]^{T}$ is a vector of regressors of the reference signal. The order of FIR path models is $M=256$, and the order of the equalizing filters is $N=256$ for all experiments. These values have been chosen based on impulse response analyses.

The $j$-th control signal $u_{j}$ is calculated as:

$$
u_{j}(i+1)=\underline{w}_{j}(i)^{T} \underline{x}_{u}(i)
$$

where $\underline{x}_{u}(i)=[x(i), x(i-1), \ldots, x(i-N+1)]^{T}$.

For all of the experiments, the sampling frequency was set to $2 \mathrm{kHz}$, and 8th order Butterworth low-pass analogue filters with $600 \mathrm{~Hz}$ cut-off frequency were used as antialiasing and reconstruction filters. An additional high-pass digital filter with a transfer function equal to $\left(1+z^{-1}\right) /\left(1-0.999 z^{-1}\right)$ was used for microphone measurements to filter out the DC offset.

\subsection{Distribution of the control signal to multiple actuators}

The proposed system uses three actuators to radiate secondary sound for reducing noise at the point of interest, or playing sound back. Thus, it is an underdetermined control system, and the same output can be generated by many different control signals (Elliott 2001). However, it has a potential to radiate a higher acoustic power as compared to a single actuator case. Other criteria can be defined to force the required effort distribution for the actuators. They can refer to multi-band processing or control signal limits. A similar possibility exists in classical multi-way loudspeakers, where crossovers are used. The input signal is then filtered by different fixed-parameter band-pass filters, one for each speaker.

Without limits on the control signals, the applied algorithm distributes control signal energy to all actuators dependent on the properties of the subsequent secondary paths. Saturation of control signals can cause convergence of the control filters to filters far from optimal ones (see Fig. 4).
This can particularly happen when one control signal saturates, while other control signals are still far from saturation. Such a scenario is quite common when operating near maximum possible radiated power.

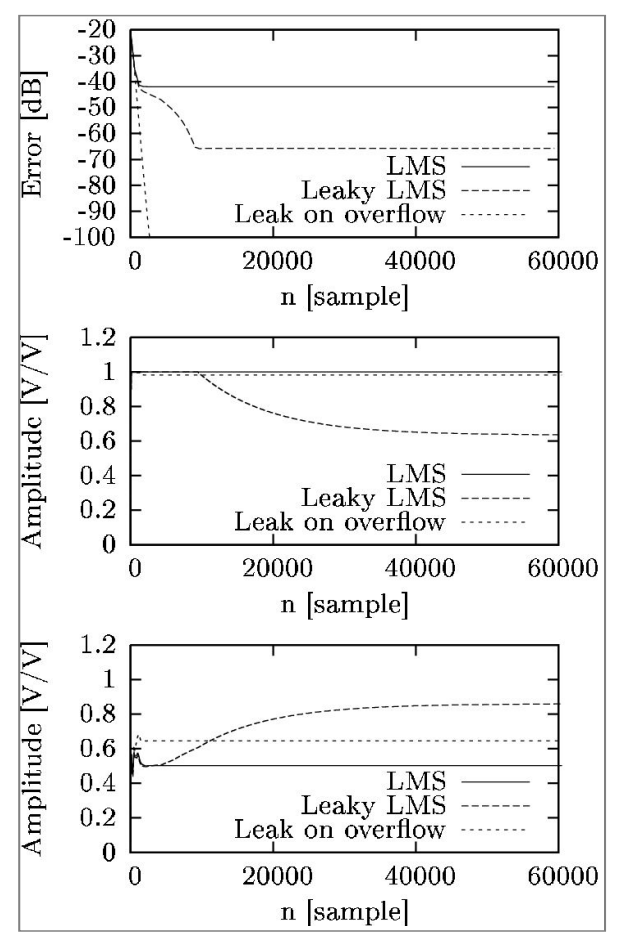

Fig. 4. Convergence in case of saturation for the generation of tonal sound (simulation)

A small leak applied to the LMS algorithm is sufficient for a better distribution of power to the multiple actuators. For $\alpha=0.99999$ this process is, however, very slow. To overcome this problem it is proposed to apply a much higher leak of $\alpha=0.999$ for 16 samples for the channel, for which control signal saturation is encountered. Such an operation quickly solves the saturation problem for the given actuator and allows for the proper adaptation of other control filters. Without a leak, when none channel is in saturation, the optimal solution is found.

\subsection{Desired response and equalization results}

In the ideal scenario, for full equalization the desired signal and the sound radiated by the vibrating plate should be equal at the point of interest. However, this is impossible for a general case, because the equalizing filters should be noncausal to invert the effect of delays in the secondary paths. Such an obligation does not apply to a deterministic signal, for which the equalizing filters are able to predict future samples of the signal. The equalizing filters are then signal-specific. Any nonstationarity of the signal results in a control filter mismatch and a need for its update. For a stochastic signal, the LMS-based adaptation algorithm minimises the instantaneous square value of the error signal, what results in reducing the signal to a certain level, instead of cancelling it. 
To avoid requiring the equalizing filters work as predictors, the desired signal at the point of interest can be considered as the input signal filtered though a linear filter $H$ of a sufficient group delay, which models the desired path between the input and the output. For most purposes a $k$-sample pure delay filter is the best choice, because it has a unity magnitude. It also coincides with the equalization assumption. With this filter, if the equalization is perfect the vibrating plate acts as a pure delay, and is recognised by the ANC system as a simple plant.

The resulting amplitude response of the vibrating plate with the equalizing filters for various delays $k$ and white noise input signal is shown in Figure 5. For all cases, variations of the amplitude response are much lower than in the case of driving the actuators directly (see Fig. 2). For low frequencies, the equalizing system is unable to compensate the very low radiation of the vibrating plate because of limits on the control signal. A higher delay in the desired path allows for a flatter amplitude response.

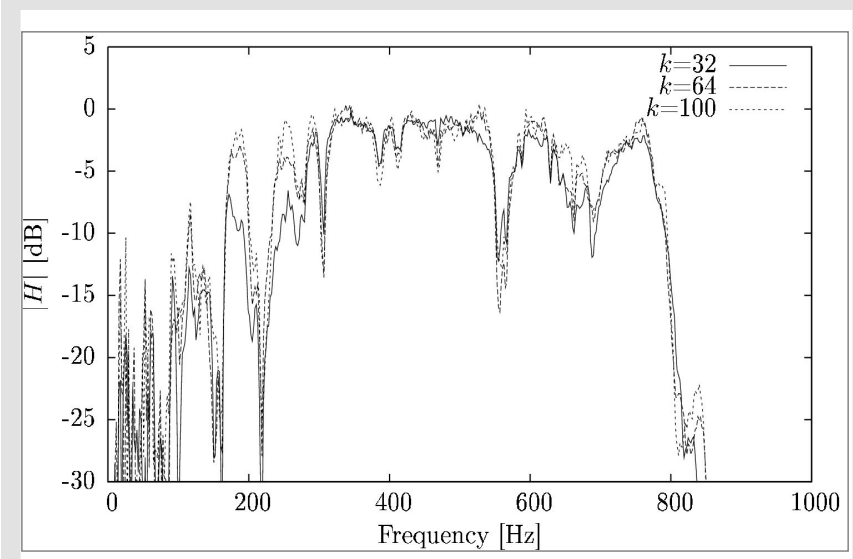

Fig. 5. Amplitude response of the secondary path with the linear equalizer for different delays

The phase response is very close to the desired one for medium frequencies, even for $k=32$ (see Fig. 6). This confirms the efficiency of the equalizing algorithm, which operates both in terms of amplitude response and phase response at the same time.

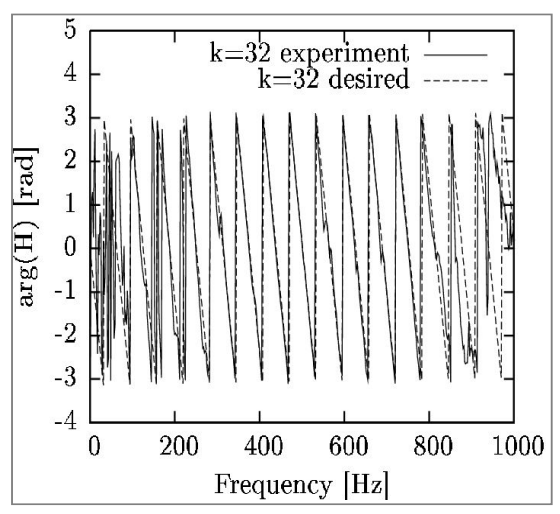

Fig. 6. Phase response of the plate with the linear equalizer

\section{EQUALIZED PLANT IN APPLICATIONS}

It has already been announced that the equalized vibrating plate can be used as sound source for playback systems and ANC applications. The delay introduced due to the desired response does not have any negative effects for the playback system. For off-line applications also future samples processed in frames that can be used to eliminate the effect of the delay.

For adaptive ANC systems the delay is less important as long as it does not change in time. ANC systems, in turn, prefer a lower delay to guarantee causal operation. Otherwise, noise reduction results would be poor for a stochastic noise case. Making the response of the plant close to the response of a pure delay significantly simplifies the design of the ANC system. The design and analysis of an ANC system is beyond the scope of this paper.

\section{CONCLUSIONS}

In this paper the problem of sound radiation from the vibrating has been considered. It has been shown that feed-forward linear adaptive filters can be used for equalizing the vibrating plate sound radiation. The spread in the response for different frequencies becomes much smaller. It has also been shown that exciting the plate by one actuator is insufficient to use the plate as a general purpose loudspeaker. The major limitation is the low acoustic power. In linear control, at low frequencies, the amplitude is decreased to equalize the overall characteristic. The amplitude cannot be increased because for the maximum input amplitude the resulting control signal would be saturated. A non-linear controller can also be applied to generate additional power for some frequencies by exciting other frequencies. In this paper another approach has been used.

Multiple actuators on a single plate effectively excite more vibration modes than a single actuator and emit a higher acoustic power. With the proposed filter the vibrating plate with multiple actuators can thus operate as a single-input loudspeaker. For most applications, the speaker must have only one input. For other applications like ANC, this can significantly reduce the number of output channels in the controller. This can be very important for large ANC systems, for instance for large industrial halls.

\section{Acknowledgements}

The research reported in this paper has been partially supported by the Ministry of Higher Education and Science, Poland, under grant no. N N514 232037.

\section{References}

Cieślik J, Bochniak W. 2010, Examination on the dependence of acoustic power radiation and the vibration energy flow in rectangular plates, 57th Open Seminar on Acoustics 2010, Gliwice, September 20-24, ISBN 978-83-931744-0-9, pp. 45-48. 
El Kadiri M., Benamar R., White R.G. 1999, The non-linear free vibration of fully clamped rectangular plates: second non-linear mode for various plate aspect ratios, Journal of Sound and Vibration, 228(2), pp. 333-358.

Elliott S. 2001, Signal Processing for Active Control, London, Academic Press.

Fahy F., Gardonio P. 2007, Sound and Structural Vibration, 2nd ed., Elsevier.

Hansen C.H., Snyder S.D. 1997, Active Control of Noise and Vibration, E \& FN Spon, First Edition.

Kuo S.M., Morgan D.R. 1996, Active Noise Control Systems, New York, John Wiley \& Sons, Inc.
Pawełczyk M. 2005, Feedback Control of Acoustic Noise at Desired Locations, Silesian University of Technology, Gliwice.

Pietrzko S.J. 2009, Contributions to Noise and Vibration Control Technology, AGH - University of Science and Technology Press, Kraków.

Saha K.N., Misra D., Ghosal S., Pohit G. 2005, Nonlinear free vibration analysis of square plates with various boundary conditions, Journal of Sound and Vibration, 287, pp. 1031-1044.

Smart Material: $M F C$, Retrieved October 14th, 2010 from http:// www.smart-material.com/Smart-choice.php?from=MFC.

Wiciak J. 2008, Sound radiation by set of L-jointed plates with four pairs of piezoelectric elements, The European Physical Journal Special Topics, 154, 1, pp. 229-233. 